\title{
Dietary Salt Intake and Hypertension
}

Sung Kyu Ha, M.D.

Renal Division, Department of Internal Medicine, Gangnam Severance Hospital, Yonsei University

College of Medicine, Seoul, Korea
Received: June 13, 2014

Accepted: June 17, 2014

Corresponding Author: Sung Kyu Ha, M.D., Ph.D.

Renal Division, Department of Internal Medicine,

Gangnam Severance Hospital, Yonsei University

College of Medicine, Seoul, Korea

Tel: +82-2-2019-3313, Fax: +82-2-3463-3882

E-mail: hask1951@yuhs.ac
Over the past century, salt has been the subject of intense scientific research related to blood pressure elevation and cardiovascular mortalities. Moderate reduction of dietary salt intake is generally an effective measure to reduce blood pressure. However, recently some in the academic society and lay media dispute the benefits of salt restriction, pointing to inconsistent outcomes noted in some observational studies. A reduction in dietary salt from the current intake of $9-12 \mathrm{~g} /$ day to the recommended level of less than $5-6 \mathrm{~g} /$ day will have major beneficial effects on cardiovascular health along with major healthcare cost savings around the world. The World Health Organization (WHO) strongly recommended to reduce dietary salt intake as one of the top priority actions to tackle the global non-communicable disease crisis and has urged member nations to take action to reduce population wide dietary salt intake to decrease the number of deaths from hypertension, cardiovascular disease and stroke. However, some scientists still advocate the possibility of increased risk of CVD morbidity and mortality at extremes of low salt intake. Future research may inform the optimal sodium reduction strategies and intake targets for general populations. Until then, we have to continue to build consensus around the greatest benefits of salt reduction for CVD prevention, and dietary salt intake reduction strategies must remain at the top of the public health agenda.

Key Words: Dietary salt, Restriction, Target, Hypertension

This is an Open Access article distributed under the terms of the Creative Commons Attribution Non-Commercial License (http://creativecommons.org/licenses/by-nc/3.0/) which permits unrestricted non-commercial use, distribution, and reproduction in any medium, provided the original work is properly cited.

\section{Introduction}

Recently, there has been a hot debate over whether current salt intake is too high from a health perspective. It is estimated that globally $62 \%$ of cerebrovascular disease and $49 \%$ of ischaemic heart disease were attributable to elevated blood pressure. A technical report produced by WHO and the Food and Agriculture Organization of the United Nations recommended the consumption of less than $5 \mathrm{~g}$ of salt per day as a population nutrient intake goal. Given the adverse impact of excessive salt consumption on health and particularly on blood pressure levels and cardiovascular diseases, the World Health Organiztion has urged member nations to take action to reduce population wide dietary salt intake to decrease the number of deaths from hypertension, cardiovascular disease and stroke (WHO report 2006) ${ }^{1)}$. Salt is an ionic compound composed of sodium chloride, which is $40 \%$ sodium and $60 \%$ chloride. Salt crystals are translucent and cubic in shape, they normally appear white. The molar mass of salt is $58.443 \mathrm{~g} / \mathrm{mol}$, its melting point is $801^{\circ} \mathrm{C}\left(1,474^{\circ} \mathrm{F}\right)$ and its boiling point $1,465^{\circ} \mathrm{C}\left(2,669^{\circ} \mathrm{F}\right)$. Salt is readily soluble in water and dissolved in water it separates into $\mathrm{Na}^{+}$and $\mathrm{Cl}^{-}$ions. Over the past century, sodium chloride has been the subject of intense scientific research related to blood pressure (BP) elevation and cardiovascular mortalities. However, recently some in the academic society and lay media dispute the benefits of salt restriction, pointing to inconsistent outcomes noted in some observational studies ${ }^{2,3)}$.

\section{Brief history of Salt}

For millions of years, human beings ate very small amo- 
unts of salt (0.1-0.5 g/day). Among the food that humans ingest, meat has the highest salt content (about $0.6 \mathrm{~g}$ of salt per pound). During the hunter-gathering period, the main food for human being was meat. Their diet consisted of $50 \%$ meat and 50\% plants. So the intake of salt in paleolithic times was less than $1 \mathrm{~g} /$ day. In the mean times, population growth led to the introduction of agriculture, and during the first few thousand years after the advent of agriculture, the intake of meat declined and the intake of vegetables increased up to $90 \%$. In the agricultural period, human beings consumed about the same amount of salt as did their hunter-gathering ancestors ${ }^{4}$. The earliest evidences of salt processing dates back to around 6,000 years ago. People living in Romania were boiling the salt-laden spring water to extract the salts. The harvest of salt from the surface of Xiechi Lake near Yuncheng in Shanxi, China, dates back to at least $6000 \mathrm{BC}$, making it one of the oldest verifiable saltworks ${ }^{5}$. Salt was required as a food preservative for thousands of years. About 5,000 years ago, the Chinese discovered that salt could be used to preserve food. Salt then became of great economic importance as it was possible to preserve food during the winter and allowed the development of settled communities. With the increased use of salt, salt became a precious commodity of commerce. About 1,000 years ago, salt intake in the western world had risen to about $5 \mathrm{~g} /$ day $^{6}{ }^{6}$. Herodotus, an ancient Greek historian, described salt trading routes that united the salt oases of the Libyan desert back in the $5^{\text {th }}$ century BC. In the early years of the Roman Empire, roads such as the Via Salaria were built for the transportation of salt from the salt pans of Ostia to the capital ${ }^{7}$. With the spread of civilization, salt became one of the world's main trading commodities. Much of the food they ate contained salt and its consumption was increasing consequently. The oppressive salt tax in France was one of the causes of the French Revolution. In India, this tax gave rise to a civil disobedience campaign under Mahatma Ghandi against the British ${ }^{8)}$.

\section{Salt and Human living}

Salt is an essential electrolyte to life in human beings and is used universally in cooking, seasoning, and preserving manufactured food stuffs around the world. For several million years, human ancestors ate a diet that contained less than $1 \mathrm{~g}$ of salt per day. Salt was the most taxed and traded commodity in the world, with intake reaching a peak around the $19^{\text {th }}$ century ${ }^{9}$. . However, salt was no longer required as a food preservative with the invention of the refrigerator. Salt intake had been declining, but with the recently large increase in the consumption of highly salted processed food, salt intake is increasing towards levels similar to those of the $19^{\text {th }}$ century, and is approximately 9-12 g/day in most countries around the world ${ }^{10)}$. Most table salt sold for consumption contains additives. The amounts of additives vary widely from country to country. Iodine is an important micronutrient for humans and iodized table salt has significantly reduced disorders of iodine deficiency. Salt is present in most foods we eat. However, in naturally occurring foods such as meats, vegetables, and fruits, salt is present in small quantities. There is more salt in animal tissues such as meat, blood and milk, than there is in plant tissues ${ }^{11)}$. Nomads hunted and ate the meat within a few hours of the kill. They do not eat salt with their food, but agriculturalists, feeding mainly on cereals and vegetables, need to supplement their diet with salt ${ }^{12}$. Recently many processed foods use large amounts of salt and over $75 \%$ of daily sodium intake comes from salt found in processed foods.

\section{Salt intake, Blood pressure, and Human health}

Sodium serves as an important nutrient in the body and helps nerves and muscles to function correctly. It is also involved in the auto-regulation of the water and fluid balance of the body. High dietary salt intake presents a major challenge to the kidneys to excrete large amounts of salt administered. One of the main organ systems vulnerable to the adverse effects of excessive sodium in the diet is the cardiovascular system. Excess dietary sodium predisposes to high $\mathrm{BP}^{13,14)}$. Changes in salt intake are associated in general with corresponding changes in arterial BP. The earliest comment relating dietary salt intake 
to BP was by the Chinese medical doctor in $2698-2598$ BC (Huang Ti Nei Ching Su Wen; The Yellow Emperor's Classic of Internal Medicine): "therefore if large amounts of salt are taken, the pulse will stiffen or harden"15). The association between salt intake in the diet and BP was first suggested by Ambard and Beaujard in 1904 ${ }^{16}$. They studied 6 patients with high BP for 3 weeks. They used three kinds of salt and protein content of diets. Salt intake was measured by estimating the salt content of the food and the urine each day. When the diet contained little salt, the patients went into negative sodium balance and blood pressure fell, even though the intake of protein was raised. Conversely, when the diet was high in salt, less salt was excreted in the urine so that the patient was in positive sodium balance and the BP rose even when the protein intake was low. They concluded that it was the salt that primarily affected BP. They had some success in reducing BP by restricting salt intake.

In 1948, Kempner introduced rice diets for the treatment of hypertension. He treated 500 hypertensive patients with a diet containing $20 \mathrm{~g}$ of protein, little fat, and $<0.5 \mathrm{~g}$ salt. It mainly consisted of rice and fruit. $\mathrm{He}$ showed that rice diets containing little salt improved BP, decreased heart size, reversed inverted $\mathrm{T}$ waves in the EKG, and ameliorated hypertensive retinopathy. However, a rice diet did not have widespread acceptability because of insipid and unpalatable features of food contents. The connection between high salt intake and elevated BP became widely recognized after Kempner's rice diet in 1948 and thus, high BP was lowered by a low salt diet and a renewed salt restriction strategy utilized in the treatment of hypertension ${ }^{17)}$. Since then, many animal studies showed a causal relationship between dietary sodium and hypertension and in human studies, established that the average BP in the population is related to habitual salt intake $\mathrm{e}^{13)}$. The available data in animal studies confirm the existing relationship between habitual salt intake and BP levels. A well-documented connection between hypertension and dietary salt intake has been demonstrated in various animals, especially in rats and chimpanzees. Ball and Meneely ${ }^{18)}$ reported that in groups of young adult rats that were fed different amounts of salt in their diet $(0.15,2.8,5.6,7.8$, or 9.8\%) with free access to distilled water, the average BP after 9 month increased proportionally to the amount of salt in their diet. A similar study had been performed in chimpanzees, which are genetically very close to humans, by Denton et al. ${ }^{19)}$. Chimpanzees normally consume a diet low in salt, but when their salt intake increased to $\sim 15 \mathrm{~g} /$ day for 20 months, they developed hypertension. The rise in BP was gradual and it was still rising 18 months after they started the high salt diet. Moreover, when the salt was reduced from the diet containing $\sim 15 \mathrm{~g}$ salt/day to $0.5 \mathrm{~g}$ salt/day, blood pressure levels fell back to the original level after 6 months. In this study, we can see a progressive increase in BP with added salt and this was completely reversible when the added salt was stopped. Experiments in chimpanzees strongly suggest that essential hypertension is due to high salt intake.

Studies on the effect of salt intake on BP in humans have been carried out extensively for the past several decades. After Kempner's rice diet in 1948, other investigators showed the BP lowering effect of a low salt diet ${ }^{20)}$. However, it was a very difficult thing to reduce the salt intake below $1 \mathrm{~g} /$ day in the everyday food intakes in humans. Regional differences in habitual salt intake and BP within a population have been studied in various areas of the world. Around the Newfoundland area, a survey of salt intake revealed that a county in the center of the island had a typical salt intake varying between 6.7 and 7.3 $\mathrm{g} /$ day. In contrast, the salt intake varied between 8.4 and $8.8 \mathrm{~g}$ /day in a relatively isolated coastal community ${ }^{21}$. This difference in salt intake was accompanied by parallel changes in the incidence of hypertension. In individuals aged between 55 and 75 years, the incidence of hypertension in the inland community was $15 \%$ while it was $27 \%$ in the coastal community. Similar evidence had been obtained among the Solomon Islanders ${ }^{22)}$. In those tribes, which lived away from the coast and had a salt intake below $2 \mathrm{~g} /$ day, only $1 \%$ of the population had a raised BP. In two tribes with salt intakes between 3 and $8 \mathrm{~g} /$ day, $3 \%$ of the population had a raised BP. In one tribe, which 
lived on the coast and had a salt intake between 9 and $15 \mathrm{~g} /$ day, $8 \%$ of the population had a raised BP. Migratory studies also provide evidences of a relationship between habitual salt intake and BP. Studies of population groups that migrated from areas with lower salt intake to areas with higher salt intake have reported increases in BP. A carefully controlled study from Kenya showed that the migrants who had higher mean urinary sodium/potassium ratio compared to the non-migrants had higher systolic $\mathrm{BP}^{23)}$. Blood pressure in these migrants rose after a few months $(6.9 / 6.2 \mathrm{mmHg}$ for systolic and diastolic), whereas it did not increase in a control group who did not migrate $^{24)}$. Another example of the effect of life-style changes including dietary sodium intake on BP is that of the Yi people, an ethnic minority living in southwestern China. Blood pressure rose very little with increasing age (0.13 and $0.23 \mathrm{mmHg} /$ year for systolic and diastolic, respectively) in the Yi farmers who lived in a remote mountainous environment and consumed a sodium-poor diet. In contrast, Yi migrants and Han people who lived in urban areas consumed a sodium-rich diet and experienced a much greater increase in BP with progressive aging $(0.33$ and $0.33 \mathrm{mmHg} /$ year for systolic and diastolic, respectively) ${ }^{25)}$. These findings suggest that changes in life-style, including higher intake of dietary sodium, contributed to higher BP among Yi migrants.

A large number of epidemiologic, evolutionary, and clinical studies have confirmed that salt intake is an important factor in elevating the BP in humans. The first double-blind controlled study of moderate salt restriction was performed in the early 1980's by MacGregor et al. ${ }^{26}$. They recruited nineteen unselected patients with mild to moderate essential hypertension, whose average supine BP after two months' observation and no treatment was $156 / 98 \mathrm{mmHg}$. Patients were advised to reduce dietary salt intake. After 2 weeks of sodium restriction, patients were entered into an 8-week double-blind randomized crossover study of 'Slow Sodium' (Ciba, 10 mmol of sodium per tablet) versus slow sodium placebo. The mean supine BP was $7.1 \mathrm{mmHg}(6.1 \%)$ lower in the fourth week of slow sodium placebo than that in the fourth week of slow sodium Ciba $(\mathrm{p}<0.001)$. Urinary sodium excretion in the fourth week of slow sodium Ciba was $162 \pm 9 \mathrm{mmol} / 24$ hours and that in the fourth week of slow sodium placebo was $86 \pm 9 \mathrm{mmol} / 24$ hours $(\mathrm{p}<0.001)$. They suggested that moderate sodium restriction should become part of the management of essential hypertension. Followed by this study, many large observational and epidemiological investigations conducted worldwide link between high salt intake and hypertension.

INTERSALT study was one of the first large international epidemiologic studies on sodium intake and hypertension using a standardized method for measuring 24hour urinary sodium. This study, which was a crosssectional assessment of 10,079 subjects aged 20-59 sampled from 52 centers around the world, attempted to relate sodium intake to BP from an epidemiological perspective. Sodium excretion ranged from $0.2 \mathrm{mmol} / 24$ hours (Yanomamo Indians, Brazil) to $242 \mathrm{mmol} / 24$ hour (north China). In individual subjects (within centers), salt intake was significantly related to BP. Four centers found very low sodium excretion, low BP, and little or no upward slope of BP with age. Across the other 48 centers sodium was significantly related to the slope of BP with age but not to median BP. The study demonstrated a significant positive relationship between salt intake and BP in individual subjects within centers. In an initial analysis of 48 of the 52 centers, no significant association between sodium intake and median BP was found. However, after inclusion of the remaining 4 centers, in which the average sodium consumption was $0.2-50 \mathrm{mmol} /$ day, they found a significant association between salt intake and the increase in BP with age. Furthermore, it also found that populations with low average daily salt intakes had low BP and very little or no increase in BP with age ${ }^{27}$. INTERSALT study indicates that $\mathrm{BP}$ increases with age only if accompanied by increased salt intake. As part of the INTERSALT study, $\mathrm{BP}$, urinary electrolytes, age, and body mass index were assessed in a sample of 195 Yanomamo Indians from the Brazilian Amazon ${ }^{28)}$. Mean sodium excretion was $0.9 \mathrm{mmol} /$ day. Urinary sodium was lower than $1 \mathrm{mmol} /$ day in $84 \%$ of participants. Mean BP was $96.0 / 60.6 \mathrm{mmHg}$ (range 
$78 / 37$ to $128 / 86$ ). Systolic and diastolic BP were not higher at older than at younger ages in men. In women, systolic pressure was lower at older ages. In this tribe, there was a low average population BP, no hypertension and no positive slope of BP with age in a population with very low salt intake. Salt institute criticized that in an initial analysis of 48 of the 52 centers, no significant association was noted between sodium intake and median BP. However, the INTERSALT's investigators re-analyzed their data and showed that the highly significant within-population association between salt intake and BP across all 52 centers was virtually unchanged. Lowering sodium intake by $100 \mathrm{mmol}$ was associated with a $3 \mathrm{mmHg}$ decrease in systolic $\mathrm{BP}^{29)}$.

There are several studies on the effect of reducing the salt intake on BP on a community levels. Forte et al. ${ }^{30)}$ studied reducing the dietary salt intake on BP on a community in Portugal, which is notorious for its high consumption of salt. The trial was performed in two communities within the same district, each with 800 inhabitants who had salt intakes of $\sim 21 \mathrm{~g} /$ day and a $30 \%$ incidence of hypertension. In the intervention community, there was a widespread health education effort to reduce the dietary salt intake. The reduction in salt intake in one of the communities to $\sim 12 \mathrm{~g} /$ day was associated with a highly significant difference in BP. By the end of the second year, there was a small rise in systolic BP in the control community and a significant fall in both systolic and diastolic BP in the low salt intake community, the difference between the two villages reached $13 / 6 \mathrm{mmHg}$. The fall in BP involved the whole community, normotensives and hypertensive individuals alike, and the response did not differ between the young and the old or between men and women. Those with the greatest fall in salt excretion tended significantly to be also those who showed the greatest fall in BP. The other long-term trial was carried out in Tianjin in China as part of a community-based intervention program to reduce non-communicable diseases ${ }^{31}$. This intervention was based on examinations of independent cross-sectional population samples in 1989 (1,719 persons) and 1992 (2,304 persons) in the intervention and matched reference areas. The food recall method was used to measure dietary salt intake. The mean reduction in salt intake was $1.3 \mathrm{~g} /$ day in men and $0.7 \mathrm{~g} /$ day in women in the intervention area from 1989 to 1992 . During the same period, the sodium intake increased significantly in men of the reference area. The reduction was statistically significant in men $(p<0.001)$ and near significant in women $(\mathrm{p}<0.05)$. In the intervention area, the mean systolic $\mathrm{BP}$ decreased by $3 \mathrm{mmHg}$ for the total population and by $2 \mathrm{mmHg}$ for normotensive people. The decrease in systolic BP was significant for both hypertensive and normotensive subjects. Another long-term trial was performed in two Belgian towns of 12,000 and 8,000 inhabitants, situated within $50 \mathrm{~km}$ of each other ${ }^{32)}$. The low-sodium intervention in one town was mainly directed at women and implemented through mass media techniques, while the control town was merely observed. Cross-sectional random sampling at baseline and 5 years later was employed, the participation rate being similar (67\%) in the two towns. During the study a total of 2,211 subjects were examined. In adult women (greater than or equal to 20 years) in the intervention town the 24-hour urinary excretion of sodium (UVNa) decreased by $25 \mathrm{mmol} / 24 \mathrm{~h}(\mathrm{p}<0.001)$ and this reduction differed $(p=0.01)$ from the concurrent trend in UVNa in the control town $(+8 \mathrm{mmol} / 24 \mathrm{~h})$. However, both systolic $\mathrm{BP}(-7.5$ versus $-7.9 \mathrm{mmHg})$ and diastolic $\mathrm{BP}(-2.3$ versus $-3.0 \mathrm{mmHg}$ ) declined to a similar extent in the women from the two towns. In adult men in the intervention town, decreases were observed in UVNa $(-12 \mathrm{mmol} / 24 \mathrm{~h})$ and in systolic BP (-5.6 mmHg) and diastolic BP (-2.4 $\mathrm{mmHg}$ ), but these trends were not significantly different from the concurrent changes in the control town (-14 $\mathrm{mmol} / 24 \mathrm{~h},-4.9$ and $+0.2 \mathrm{mmHg}$, respectively). No significant difference was observed in the evolution of mean systolic and diastolic pressures that declined to the same extent in the two towns during the trial. In women of the intervention town, 24-hour urinary salt excretion decreased by $1.5 \mathrm{~g}$, whereas in the control town it rose by $0.5 \mathrm{~g}$. This negative result may be explained by the small reduction in salt consumption that would be insufficient 
to observe a net effect on BP in the Belgian environment. These results suggest that a reduction in salt consumption is difficult to achieve with mass media techniques and in women and in subjects aged 50 years or more, the intervention did achieve some success, but BP was not affected.

There were many randomized clinical trials performed to test the effects of reducing salt intake on BP. Cutler et al. ${ }^{33)}$ analyzed previously published randomized clinical trials testing the effects of reducing sodium intake on BP. Thirty-two trials with outcome data for 2,635 subjects were included. Pooled BP differences between treated and control groups were highly significant for all trials combined. The effects on blood pressure by lowering sodium in hypertensive and normotensive subjects were $-4.8 /-2.5$ and -1.9/-1.1 mmHg (systolic/diastolic), respectively. Median differences in sodium excretion between sodium-reduction and control groups in these subgroups were -77 and $-76 \mathrm{mmol} / 24 \mathrm{~h}$, respectively. Weighted linear-regression analyses across the trials showed dose responses, which were more consistent for trials in normotensive subjects. These analyses yielded estimates, per $100 \mathrm{mmol}$ of sodium reduction, of $-5.8 /-2.5 \mathrm{mmHg}$ in hypertensive subjects and $-2.3 /-1.4 \mathrm{mmHg}$ in normotensive subjects, respectively. There is no evidence that sodium reduction as achieved in these trials presents any safety hazards. They concluded that the BP reduction with a substantial lowering of dietary sodium in the US population could reduce cardiovascular morbidity and mortality. However, in two other meta-analyses ${ }^{34,35)}$, it was claimed that salt reduction had very little effect on BP in individuals with normal BP and a reduction in population salt intake was not warranted. The meta-analysis by Midgley et al. ${ }^{34)}$ included 56 trials that had randomized allocation to control and dietary sodium intervention groups with outcome measures of both systolic and diastolic BP. The mean reduction in daily urinary sodium excretion was $95 \mathrm{mmol} /$ day (71-119 mmol/day) in 28 trials with 1,131 hypertensive subjects and $125 \mathrm{mmol} /$ day $(95-156 \mathrm{mmol} /$ day) in 28 trials with 2,374 normotensive subjects. The decrease in BP for a $100 \mathrm{mmol} /$ day reduction in daily sodium excretion was $3.7 \mathrm{mmHg}(2.35-5.05 \mathrm{mmHg})$ for systolic $(\mathrm{p}<$
$0.001)$ and $0.9 \mathrm{mmHg}(-0.13$ to $1.85 \mathrm{mmHg})$ for diastolic $(\mathrm{p}=0.09)$ in the hypertensive subjects, and $1.0 \mathrm{mmHg}(0.51$ $-1.56 \mathrm{mmHg})$ for systolic $(\mathrm{p}<0.001)$ and $0.1 \mathrm{mmHg}(-0.32$ to $0.51 \mathrm{mmHg}$ ) for diastolic $(\mathrm{p}=0.64)$ in the normotensive subjects. Decreases in BP were larger in trials of older hypertensive individuals and small and non-significant in trials of normotensive individuals. They concluded that dietary sodium restriction for older hypertensive individuals might be considered, but the evidence in the normotensive population does not support current recommendations for universal dietary sodium restriction. Another meta-analysis by Graudal et al. ${ }^{35)}$ included 58 trials of hypertensive and 56 trials of normotensive person to evaluate the effect of sodium restriction to blood pressure lowering. In 58 trials of hypertensive subjects, the effect of reduced sodium intake as measured by urinary sodium excretion (mean, $118 \mathrm{mmol} / 24 \mathrm{~h}$ ) on systolic BP was 3.9 $\mathrm{mmHg}(\mathrm{p}<0.001)$ and on diastolic BP was $1.9 \mathrm{mmHg}(\mathrm{p}$ $<0.001$ ). In 56 trials of normotensive subjects, the effect of reduced sodium intake (mean, $160 \mathrm{mmol} / 24 \mathrm{~h}$ ) on systolic BP was $1.2 \mathrm{mmHg}(\mathrm{p}<0.001)$ and on diastolic BP was $0.26 \mathrm{mmHg}(\mathrm{p}=0.12)$. They concluded that these results do not support a general recommendation to reduce sodium intake. However, these two meta-analyses were criticized by some authors because the data included was flawed. Both meta-analysis included trials of very short duration with comparing the effects of acute salt loading to abrupt and severe salt restriction for only a few days. It is inappropriate to include the acute salt restriction trials in a meta-analysis where the implications of the findings are to apply them to public health recommendations for a long-term. It is possible that acute and large reduction in salt intake increases sympathetic activity, stimulates the renin-angiotensin system which would counteract the effects on BP.

Subsequently, several large-scale intervention studies showing significant antihypertensive effects of salt reduction in diet were performed by several groups. Trials of Hypertension Prevention (TOHP) phases I and II were two large randomized controlled trials enrolling 2,182 and 2,382 patients, respectively. In TOHP I ${ }^{36}$, the patients 
were randomized to three life-style change groups (weight reduction, sodium reduction, and stress management), one of which was a low sodium diet. At 18 months follow-up, weight reduction intervention produced weight loss of $3.9 \mathrm{~kg}(\mathrm{p}<0.01)$, diastolic BP change of $-2.3 \mathrm{mmHg}$ $(\mathrm{p}<0.01)$, and systolic BP change of $-2.9 \mathrm{mmHg}(\mathrm{p}<0.01)$. Sodium reduction interventions also lowered urinary sodium excretion by $44 \mathrm{mmol} / 24$ hours $(\mathrm{p}<0.01)$, diastolic BP by $0.9 \mathrm{mmHg}(\mathrm{p}<0.05)$, and systolic BP by $1.7 \mathrm{mmHg}$ $(\mathrm{p}<0.01)$. They concluded that weight reduction was the most effective strategy tested for reducing BP in normotensive persons. Sodium reduction was also effective for reducing BP. In TOHP II ${ }^{37}$, from baseline, participants' sodium excretion decreased 50 and $40 \mathrm{mmol} /$ day at 6 and 36 months in the sodium reduction group, respectively. Compared with the usual care group, BP decreased 2.9/ $1.6 \mathrm{mmHg}$ in the sodium reduction group, and 4.0/2.8 $\mathrm{mmHg}$ in the combined group (weight and sodium reduction) at 6 months (all groups, $\mathrm{p}<0.001$ ). At 36 months, BP decreases remained greater in the active intervention groups than in the usual care group (weight loss group, 1.3/0.9 mmHg; sodium reduction group, 1.2/0.7 $\mathrm{mmHg}$; combined group, 1.1/0.6 mmHg). Differences were statistically significant for systolic BP in the sodium reduction group. The long-term, 10- to 15-year Trials of Hypertension Prevention (TOHP) I and II show that, apart from lowering BP, net sodium reduction by $44 \mathrm{mmol} /$ day (TOHP I) and $33 \mathrm{mmol} /$ day (TOPH II) leads to significant reduction in cardiovascular events by $25 \%$, even after adjustment for several confounding factors. TOPH I and II will presumably remain the best evidence supporting the beneficial effect of a moderate reduction of salt intake in the general population ${ }^{38)}$.

The intervention studies of salt intake reduction are often conducted with other life-style modifications. TONE study $^{39)}$ was performed to determine whether weight loss or reduced sodium intake is effective in the treatment of older persons (aged 60 to 80 years) with hypertension. The authors randomized 585 obese participants to reduced sodium intake, weight loss, both, or usual care, and the 390 non-obese participants to reduced sodium intake or usual care. The primary endpoint included high blood pressure after discontinuation of the $\mathrm{BP}$ lowering medication at entry $(190 / 110,170 / 100$, and $150 / 90 \mathrm{mmHg}$ at 1, 2, 3 visits-not adjudicated), resuming drug treatment, inability to withdraw treatment, and cardiovascular complications (angina, myocardial infarction, stroke, heart failure, and coronary revascularization). After a median follow-up of 29 months (range 15-36 months), the composite outcome occurred less frequently among those assigned vs. not allocated to reduced sodium intake (hazard ratio $0.69 ; 95 \% \mathrm{CI}, 0.59-0.81 ; \mathrm{p}<0.001)$. The mean change in blood pressure for participants assigned to sodium reduction alone was $-3.4 \mathrm{mmHg}$ systolic and -1.9 $\mathrm{mmHg}$ diastolic, and for participants assigned to combined intervention of sodium reduction and weight loss $-5.3 \mathrm{mmHg}$ systolic and $-3.4 \mathrm{mmHg}$ diastolic, respectively ( $p<0.001$ for comparisons to usual care group). This study, however, has to be interpreted with caution including selection of adherent and well educated patients (only 11.1\% of pre-screened patients were finally randomized) and uncertain blinding. There was no difference between sodiumrestricted and control patients in the incidence of cardiovascular events (44 [12.9\%] versus 57 [16.7\%]; $\mathrm{p}=0.24$ ). TONE study showed significant antihypertensive effects of salt reduction in diet. The level of salt restriction effective for maintaining a normal BP after the discontinuation of an antihypertensive drug was $-5.6 \mathrm{~g}$ per day or less. TONE study demonstrated that a reduced sodium intake and weight loss, alone or combined, could effectively control hypertension ${ }^{39)}$.

Another well-conducted landmark study was the DASH (Dietary Approaches to Stop Hypertension)-Sodium trial ${ }^{40)}$, a 12-week well controlled feeding trial provided the most robust evidence about the effect of salt intake on human BP. It was a multi-centered clinical trial that studied three levels of sodium intake (150, 100 and $50 \mathrm{mmol} /$ day) on 412 individuals with and without hyper- tension. Each intake of salt was maintained for 30 days. Two different diets that is the control diet and the DASH diet, which is rich in fruits, vegetables and low-fat dairy products, were tested. In both groups, the participants were assig- 
ned randomly to a high sodium diet $(150 \mathrm{mmol} / \mathrm{d})$, normal sodium diet $(100 \mathrm{mmol} / \mathrm{d})$, or low sodium diet (50 $\mathrm{mmol} / \mathrm{d}$ ) for 30 days and were then crossed over within their assigned groups. When the participants were shifted from a high sodium diet to a normal sodium diet, the systolic BP decreased by $2.1 \mathrm{mmHg}(\mathrm{p}<0.001)$ in the control group and by $1.3 \mathrm{mmHg}(\mathrm{p}=0.03)$ in the DASH group. When they were shifted from a normal sodium diet to a low sodium diet, there was a further reduction in systolic $\mathrm{BP}$ of $4.6 \mathrm{mmHg}$ in the control group $(\mathrm{p}<0.001)$ and $1.7 \mathrm{mmHg}$ in the DASH group $(\mathrm{p}<0.01)$. When compared with the controls, the DASH diet led to a lower systolic BP of $7.1 \mathrm{mmHg}$ in participants without hypertension and $11.5 \mathrm{mmHg}$ in participants with hypertension. The adherence to the diet of participants was monitored, not only by measuring 24-hour urine sodium at the end of each period but also their daily food diaries. The study demonstrated that a reduction in salt intake lowered BP both on the control diet and on the DASH diet. The combination of a low salt and DASH diet had a greater effect on BP than either intervention alone. There was a very significant difference in systolic $(-6.7 \mathrm{mmHg})$ and diastolic pressure $(-3.5 \mathrm{mmHg})$ between participants on the $150 \mathrm{mmol}$ sodium/day diet and those on the $50 \mathrm{mmol}$ sodium/day. The blood pressures were all significantly lower on the DASH diet. There was a greater reduction in systolic pressure when blood pressure was initially high and in women, but most importantly the blood pressurelowering effect of reducing the salt intake was observed in all categories of the population, in particular in normotensive as well as in hypertensive people. The DASH-sodium trial supports that a low sodium diet leads to lower blood pressure. This observation is very important for the public health issue of lowering salt intake. Most acknowledge that this study reliably confirmed the benefit of dietary sodium restriction in BP management. However, the DASH diet was significantly different from the control diet in terms of more fruits, vegetables, low-fat dairy foods, fish, nuts, potassium, calcium, magnesium, and dietary fiber. Although the group on the DASH diet had a lower urinary sodium excretion, this does not necessa- rily imply that the benefit was being solely caused by a dietary sodium reduction. In addition, this study did not evaluate the long-term effects of the intervention and the clinically relevant variables, such as mortality or morbidity. After the DASH-Sodium trial, many meta-analyses of intervention studies were investigated. In 2002, He and MacGregor ${ }^{41)}$ demonstrated that a modest salt intake reduction caused significant falls in BP in both hypertensive and normotensive individuals. In this study, a total of 17 trials in hypertensives $(n=734)$ and 11 trials in normotensives $(n=2,220)$ were included. The median reduction in 24-hour urinary sodium excretion was 78 mmol in hypertensives and $74 \mathrm{mmol}$ in normotensives. The pooled estimates of BP fall were 4.96/2.73 $\pm 0.40 /$ $0.24 \mathrm{mmHg}$ in hypertensives $(\mathrm{p}<0.001)$ and $2.03 / 0.97 \pm$ $0.27 / 0.21 \mathrm{mmHg}$ in normotensives $(\mathrm{p}<0.001)$. Weighted linear regression analyses showed a dose response relationship between the change in urinary sodium and BP. A reduction of $100 \mathrm{mmol} /$ day in salt intake predicted a fall in BP of 7.11/3.88 mmHg $(p<0.001)$ in hypertensives and $3.57 / 1.66 \mathrm{mmHg}$ in normotensive individuals $(\mathrm{p}<$ $0.05)$. They demonstrated that a modest reduction in salt intake for a duration of 4 or more weeks does have a significant and important effect on BP in both hypertensive and normotensive individuals. These findings in conjunction with other previous evidence relating salt intake to BP make a strong case for a reduction in population salt intake, which will lower population BP and therefore reduce cardiovascular mortality. Many meta-analyses, so far, on the effect of salt reduction on BP have shown consistent reductions in $\mathrm{BP}$ in those with high blood pressure, but there has been some controversy about the magnitude of the fall in BP in normotensive individuals ${ }^{34,36}$. In these two meta-analyses, it was claimed that salt reduction had no or very little effect on blood pressure in normotensive individuals. However, detailed examination of these two meta-analyses showed that their data collection and analysis were flawed.

Recently, there has been a hot debate whether current salt intake is too high from a health perspective. There were studies reporting the influence of salt intake on 
overall cardiovascular diseases such as $\mathrm{He}$ et al. (obese subjects) $^{42)}$ and Tuomilehto et al. $^{43)}$. They suggested that salt reduction prevented the onset of cardiovascular diseases. He et al. ${ }^{42)}$ estimated that reduction of salt intake by $3 \mathrm{~g}$ per day lowered systolic blood pressure by 5.6 $\mathrm{mmHg}$ in hypertensive individuals. They also found that it was the obese and not the non-obese who benefited. Tuomilehto et al. ${ }^{43)}$ prospectively followed 1,173 Finnish men and 1,263 women aged 25-64 years with complete data on 24 hour urinary sodium excretion and cardiovascular risk factors. The hazards ratios for coronary heart disease, cardiovascular disease, and all-cause mortality, associated with a $100 \mathrm{mmol}$ increase in 24 hour urinary sodium excretion, were 1.51 (95\% CI 1.14-2.00), 1.45 (1.14-1.84), and 1.26 (1.06-1.50), respectively, in both men and women. The frequency of acute coronary events rose significantly with increasing sodium excretion. They concluded that high sodium intake predicted mortality and risk of coronary heart disease, independent of other cardiovascular risk factors, including blood pressure. In a study by O'Donnell et al. ${ }^{44)}$, the tendency of an excessive salt intake-induced increase in the incidence of cardiovascular diseases was also observed. Strazzullo et al. ${ }^{45}$ ) also performed a meta-analysis of prospective cohort studies and reported that excessive salt consumption tended to increase the incidence of cardiovascular diseases. Therefore, a salt reduction strategy may be a useful tool for preventing cardiovascular diseases. However, to the contrary, Alderman et al. ${ }^{46}$ and Cohen et al. ${ }^{47)}$ repeatedly suggested that excessive salt reduction increased the incidence of cardiovascular diseases. In the presidential address of the $21^{\text {st }}$ International Society of Hypertension meeting in 2007, Alderman ${ }^{48)}$ advocated that the relationship between salt intake and the risk of cardiovascular diseases is J-shaped and that salt intake at 5 to $6 \mathrm{~g}$ per day might be characterized by the lowest risk of cardiovascular diseases. In 2011, Stolarz-Skrzypeket al. ${ }^{49)}$ reported prospective longitudinal population-based study including 3,681 people without cardiovascular disease at baseline. During a median follow up of 7.9 years, cardiovascular deaths decreased across increasing tertiles of 24-hour so- dium excretion. This significant inverse association between cardiovascular mortality and tertile of sodium excretion was retained in multivariable analyses $(p=0.02)$, with a HR (Harzard Ratio) of 1.56 in the low tertile versus the overall risk in the whole study population $(p=0.04)$. The 24-hour sodium excretion at baseline did not predict either total mortality or fatal combined with nonfatal cardiovascular events. In a subgroup of 1,499 participants who had both BP and sodium excretion measured at baseline and at last follow-up were followed up for a median of 6.1 years. The annual increases in BP averaged 0.37 $\mathrm{mmHg}$ systolic and $0.47 \mathrm{mmHg}$ diastolic $(\mathrm{p}<0.001)$, but on average the 24-hour urinary sodium excretion did not change over time. However, in multivariable-adjusted analyses of individual participants, a 100-mmol increment in 24-hour sodium excretion was associated with a significant $1.71 \mathrm{mmHg}$ increase in systolic BP $(\mathrm{p}<0.001)$, without concomitant change in diastolic BP. They concluded that lower urinary sodium excretion was associated with higher cardiovascular disease (CVD) mortality. These findings contradict a large body of evidence that established elevated salt consumption as a risk factor for CVD. However, many researchers including $\mathrm{He}$ et al. ${ }^{50)}$ criticize the results of this study. In the same year, Taylor et al. ${ }^{51)}$ published the results of a meta-analysis of intervention studies regarding salt reduction. This meta-analysis involved randomized, control studies of salt reduction in which follow-up was continued for $>6$ months; three of these studies involved normotensive individuals, two hypertensive patients and one normotensive and hypertensive combined subjects. Of these, hypertensive and normotensive individuals were separately analyzed. Salt reduction was associated with reductions in urinary salt excretion of between 27 and 39 mmol per 24 hour and reductions in systolic blood pressure between 1 and $4 \mathrm{mmHg}$. Pooled relative risks (RRs) comparing the intervention with the reference groups for all-cause mortality were 0.90 (CI, 0.58-1.40; 79 deaths) and 0.96 (CI, 0.83-1.11; 565 deaths) in normotensive and hypertensive participants, respectively. Salt restriction increased the risk of all-cause mortality in patients with heart failure (RR, 2.59; CI, 1.04- 
6.44; 21 deaths). In both hypertensive and normotensive individuals, salt reduction slightly decreased the incidence of cardiovascular diseases, although there was no significant difference. These authors found no strong evidence that salt reduction reduced all-cause mortality or CVD morbidity in normotensives or hypertensives. A single RCT showed an increase in the risk of all-cause death in those with congestive heart failure receiving a low-sodium diet. In contrast, $\mathrm{He}$ et al. ${ }^{52)}$ simultaneously analyzed normotensive individuals and hypertensive patients from the same studies including Taylor's meta-analysis. They reported that salt reduction at 2.0 to $2.3 \mathrm{~g}$ per day significantly decreased the risk of cardiovascular diseases (20\% of decrease). However, in most studies supporting the fact that salt reduction increases the risk of cardiovascular diseases, methodological problems have been indicated ${ }^{47,49)}$, or study subjects were high-risk patients ${ }^{46,51)}$.

In conclusion, a moderate reduction of dietary salt intake is generally an effective measure to reduce blood pressure. A reduction in dietary salt from the current intake of 9-12 g/day to the recommended level of less than 5-6 g/day will have major beneficial effects on cardiovascular health along with major healthcare cost savings around the world. The WHO strongly recommended to reduce dietary salt intake as one of the top priority actions to tackle the global non-communicable disease crisis and has urged member nations to take action to reduce population wide dietary salt intake to decrease the number of deaths from hypertension, cardiovascular disease and stroke. However, some scientists still advocate the possibility of increased risk of CVD morbidity and mortality at extremes of low salt intake. Future research may inform aspects of optimal sodium reduction strategies and the intake targets for populations. Until then, we have to continue to build consensus around the greatest benefits of salt reduction for CVD prevention, and dietary salt intake reduction strategies must remain at the top of the public health agenda.

\section{References}

1. World Health Organization: Reducing salt intake in po- pulations. Report of WHO Forum and Technical Meeting, Paris, 2006

2. Alderman MH: Reducing dietary sodium: the case for caution. JAMA 303:448-449, 2010

3. Kolata G: No benefit seen in sharp limits of salt in diet. The New York Times, 2013

4. MacGregor GA, de Wardener HE: Salt, Diet and Health: Neptune's Poisoned Chalice; The origin of High Blood Pressure, Cambridge, Cambridge University Press, 1998, p233

5. Kurlansky Mark: Salt: A World History, New York, Penguin Books, 2002, p18-19

6. Roberts WC: High salt intake, its origins, its economic impact, and its effect on blood pressure. Am J Cardiol 88:1338-1346, 2001

7. A brief history of salt. Time Magazine, 1982

8. Ritz E: The history of salt-aspects of interest to the nephrologist. Nephrol Dial Transplant 11:969-975, 1996

9. He FJ, Macgregor GA: Reducing population salt intake worldwide: From evidence to implementation. Prog CV dis 52:363-382, 2010

10. Intersalt Cooperative Research Group: Intersalt: an international study of electrolyte excretion and blood pressure. Results for $24 \mathrm{~h}$ urinary sodium and potassium excretion. BMJ 297:319-328, 1988

11. Buss David, Robertson Jean: Manual of Nutrition, London, Her Majesty's Stationery Office, 1981, p37-38

12. Wood, Frank Osborne: "Salt $(\mathrm{NaCl})$ ". Encyclopædia Britannica online Academic Edition, Encyclopæedia Britannica Inc., 2012

13. Meneton P, Jeunemaitre $X$, de Wardener HE, MacGregor GA: Links between dietary salt intake, renal salt handling, blood pressure, and cardiovascular diseases. Physiol Rev 85:679-715, 2005

14. He FJ, MacGregor GA: Salt, blood pressure andcardiovascular disease. Curr Opin Cardiol 22:298-305, 2007

15. Delahaye F: Should we eat less salt? Arch Cardiovasc Dis 106:324-332, 2013

16. Ambard L, Beaujard E: Causes de l' hypertension arterielle. Arch Gen Med 1:520-533, 1904

17. Kempner W: Treatment of hypertensive vascular diseasewith the rice diet. Am J Med 4:545-577, 1948

18. Ball OT and Meneely GR: Observations on dietary sodium chloride. J Am Diet Assoc 33:366-370, 1957

19. Denton D, Weisinger R, Mundy NI, Wickings EJ, Dixson A, Moisson P, Pingard AM, Shade R, Carey D, Ardaillou R, PaillardF, Chapman J, Thillet J, and Michel JB. The 
effect of increased salt intake on blood pressure of chimpanzees. Nat Med 1:1009-1016, 1995

20. Watkin DM, Froeb HF, Hatch FT, and Gutman AB: Effects of diet in essential hypertension: II. Results with unmodified Kempner rice diet in fifty hospitalized patients. Am J Med 9:441-493, 1950

21. Fodor JG, Abbott EC, and Rusted IE: An epidemiologic study of hypertension in Newfoundland. Can Med Assoc J 108:1365-1368, 1973

22. Page LB, Damon A, and Moellering RC Jr: Antecedents of cardiovascular disease in six Solomon Islands societies. Circulation 49:1132-1146, 1974

23. Poulter NR, Khaw KT, Hopwood BE, MugambiM, Peart WS, Rose G, Sever, PS: The Kenyan Luo migration study: observations on the initiation of a rise in blood pressure. Br Med J 300:967-972, 1990

24. Poulter NR, Khaw KT, Mugambi M, Peart WS, Sever PS: Migration-induced changes in blood pressure: a controlled longitudinal study. Clin Exp Pharmacol Physiol 12:211-216, 1985

25. He J, Klag MJ, Whelton PK, Chen JY, Mo JP, Qian MC, Mo PS and He GQ: Migration, blood pressure pattern, and hypertension: the Yi Migrant Study. Am J Epidemiol 134:1085-1101, 1991

26. MacGregor GA, Markandu ND, Best FE, Elder DM, Cam JM, Sagnella GA, Squires M: Double-blind randomised crossovertrial of moderate sodium restriction in essential hypertension. Lancet 1:351-355, 1982

27. Intersalt Cooperative Research Group: Intersalt: an international study of electrolyte excretion and blood pressure. Results for $24 \mathrm{~h}$ urinary sodium and potassium excretion. BMJ 297:319-328, 1988

28. Mancilha-Carvalho JJ, de Oliveira R, Esposito RJ: Blood pressure and electrolyte excretion in the Yanomamo Indians, an isolated population. J Hum Hypertens 3(5):309-14, 1989

29. Elliot P, Stamler J, Nichols R, et al. for the INTERSALT Cooperative Research Group: Intersal revisited: further analyses of 24 hour sodium excretion and blood pressure within and across populations. BMJ 312:1249-53, 1996

30. Forte JG, Miguel JM, Miguel MJ, de Padua F, Rose G: Salt and blood pressure: a community trial. J Hum Hypertens 3:179-184, 1989

31. Tian HG, Guo ZY, Hu G, Yu SJ, Sun W, Pietinen P, Nissinen A: Changes in sodium intake and blood pressure in a community-based intervention project in China. J Hum Hypertens 9:959-968, 1995
32. Staessen J, Bulpitt CJ, Fagard R, Joossens JV, Lijnen P, Amery A. Salt intake and blood pressure in the general population: a controlled intervention trial in two towns. J Hypertens 6:965-973, 1988

33. Cutler JA, Follmann D, Allender PS: Randomized trials of sodium reduction: an overview. Am J Clin Nutr 65(Suppl 2):643S-651S, 1997

34. Midgley JP, Matthew AG, Greenwood CM, Logan AG: Effect of reduced dietary sodium on blood pressure: A meta-analysis of randomized controlled trials. JAMA 275:1590-1597, 1996

35. Graudal NA, Galloe AM, Garred P: Effects of sodium restriction on blood pressure, renin, aldosterone, catecholamines, cholesterols, and triglyceride: a meta-analysis. JAMA 279:1383-1391, 1998

36. The Trials of Hypertension Prevention Collaborative Research Group: The effects of nonpharmacologic interventions on blood pressure and hypertension incidence in overweight people with high-normal blood pressure. JAMA 267:1213-1220, 1992

37. The Trials of Hypertension Prevention Collaborative Research Group: Effects of weight loss and sodium reduction intervention on blood pressure and hypertension incidence in overweight people with high-normal blood pressure: the Trials of Hypertension Prevention, phase II. Arch Intern Med 157:657-667, 1997

38. Cook NR, Cutler JA, Obarzanek E, Buring JE, Rexrode KM, Kumanyika SK, Appel LJ, Whelton PK: Long term effects of dietary sodium reduction on cardiovascular disease outcomes: observational follow-up of the Trials of Hypertension Prevention (TOHP). Br Med J 334:885-888, 2007

39. Whelton PK, Appel LJ, Espeland MA, Applegate WB, Ettinger WH Jr, Kostis JB, Kumanyika S, Lacy CR, Johnson KC, Folmar S, Cutler JA, TONE Collaborative Research Group: Sodium reduction and weight loss in the treatment of hypertension in older persons: a randomized controlled trial of nonpharmacologic interventions in the elderly (TONE). JAMA 279:839-846, 1998

40. Sacks FM, Svetkey LP, Vollmer WM, Appel LJ, Bray GA, Harsha D, Obarzanek E, Conlin PR, Miller ER III, Simons-Morton DG, Karanja N, Lin PH, DASH-Sodium Collaborative Research Group: Effects on blood pressure of reduced dietary sodium and the Dietary Approaches to Stop Hypertension (DASH) diet. N Engl J Med 344: 3-10, 2001

41. He FJ, MacGregor GA: Effect of modest salt reduction 
on blood pressure: a meta-analysis of randomized trials. Implications for public health. J Hum Hypertens 16(11): 761-70, 2002

42. He J, Ogden LG, Vupputuri S, Bazzano LA, Loria C, Whelton PK: Dietary sodium intake and subsequent risk of cardiovascular disease in overweight adults. JAMA 282:2027-2034, 1999

43. Tuomilehto J, Jousilahti P, Rastenyte D, Moltchanov V, Tanskanen A, Pietinen P, Nissinen A: Urinary sodium excretion and cardiovascular mortality in Finland: a prospective study. Lancet 357:848-851, 2001

44. O’Donnell MJ, Yusuf S, Mente A, Gao P, Mann JF, Teo K, McQueen M, Sleight P, Sharma AM, Dans A, Probstfield J, Schmieder RE: Urinary sodium and potassium excretion and risk of cardiovascular events. JAMA 306: 2229-2238, 2011

45. Strazzullo P, D’Elia L, Kandala N-B, Cappuccio FP: Salt intake, stroke, and cardiovascular disease: metaanalysis of prospective studies. Br Med J 339:b4567, 2009

46. Alderman MH, Madhavan S, Cohen H, Sealey JE, Laragh $\mathrm{JH}$ : Low urinary sodium is associated with greater risk of myocardial infarction among treated hypertensive men. Hypertension 25:1144-1152, 1995

47. Cohen HW, Hailpern SM, Fang J, Alderman MH: Sodium intake and mortality in the NHANES II follow-up study. Am J Med 119:275. e7-275.e14, 2006

48. Alderman $\mathrm{MH}$ : Presidential Address: $21^{\text {st }}$ Scientific Meeting of the International Society of Hypertension: dietary sodium and cardiovascular disease: the 'J'-shaped relation. J Hypertens 25:903-907, 2007

49. Stolarz-Skrzypek K, Kuznetsova T, Thijs L, Tikhonoff V, Seidlerová J, Richart T, Jin Y, Olszanecka A, Malyutina S, Casiglia E, Filipovský J, Kawecka-Jaszcz K, Nikitin Y, Staessen JA: European Project on Genes in Hypertension (EPOGH) Investigators: Fatal and nonfatal outcomes, incidence of hypertension, and blood pressure changes in relation to urinary sodium excretion. JAMA 305:17771785, 2011

50. He FJ, Appel LJ, Cappuccio FP, de Wardener HE, MacGregor GA: Does reducing salt intake increase cardiovascular mortality? Kidney Int 80:696-698, 2011

51. Taylor RS, Ashton KE, Moxham T, Hooper L, Ebrahim S: Reduced dietary salt for the prevention of cardiovascular disease: a meta-analysis of randomized controlled trials (Cochrane Review). Am J Hypertens 24:843-853, 2011

52. He F, MacGregor GA: Salt reduction lowers cardiovascular risk: meta-analysis of outcome trials. Lancet 378: 380-382, 2011 